\title{
MONTHLY AND SEASONAL VARIABILITY OF THE LAND- ATMOSPHERE SYSTEM
}

\author{
YONG-QIANG LIU* \\ Geargia Institute of Technology \\ Atlanta, GA 30332, USA \\ E-mail: liuy@eas.gatech.edu
}

(Manuscript received 28 January 2003)

\begin{abstract}
The land surface and the atmosphere can interact with each other through exchanges of energy, water, and momentum. With the capacity of long memory, land surface processes can contribute to long-term variability of atmospheric processes. Great efforts have been made in the past three decades to study land-atmosphere interactions and their importance to longterm variability. This paper reviews studies on monthly and seasonal variability of the landatmosphere system. Issues to be addressed include the importance of land surface processes, time scales, persistence, coupled patterns of soil moisture and precipitation, and prediction. A perspective on future studies is given.
\end{abstract}

\section{Introduction}

Land surface condition is a major factor for the partitioning of radiative energy absorbed on the ground into sensible and latent heat fluxes, which in turn affects the development of the atmospheric planetary boundary layer (PBL) and clouds. On the other hand, atmospheric processes, especially :adiation and precipitation, are driving forces of land surface thermal and hydrological variability. Therefore, the land surface and atmosphere are closely related to each other. The importance of interaction between the two climate system components has been emphasized (e.g., Shukla and Mintz 1982; Yeh et al. 1984; Mintz 1984; Xue and Shukla 1993; Avissar 1995; Betts et al. 1996).

Land-atmosphere interaction has emerged as one of the most active research areas in atmospheric and hydrological sciences in the past three decades, partly due to the increasing attention to human activity related to regional environmental changes. Landscape in Amazonia, the Sahel, and Northwest China has changed dramatically since the 1970s as a result of deforestation and over-cultivation. It might be responsible for some regional climate disasters such as the prolonged drought in northern Africa during the 1970s (Charney 1975; Xue and Shukla 1993; Zeng et al. 1999).

Great efforts have been made in developing parameterizations and datasets, and in understanding physical mechanisms. Several land surface schemes (e.g., Dickinson et al.

\footnotetext{
- Present address: Forestry Sciences Laboratory, USDA Forest Service, 320 Green St., Athens, GA 30602, USA. email: yliu@fs.fed.us
} 
1993; Sellers et al. 1986; Xue et al. 1991; Ji and Hu 1989) were developed. Parameterization schemes were also developed for heat and water transfer and convections induced by landscape heterogeneity (e.g. Chen and Avissar 1994; Zeng and Pielke 1995; Avissar and Liu 1996; Liu et al. 1999). Several datasets of decade-long soil moisture measurements have been archived (Robock et al. 2000), which are valuable for the studies of monthly and seasonal variability of the land-atmosphere system because of their long length of record. A number of feedback mechanisms were proposed (e.g., Rodriguez-Iturbe et al. 1991; Entekhabi et al. 1992; Eltahir 1998).

Similar to oceans, land has the capacity to retain anomalous signals over a much longer period than the atmosphere. This suggests that land surface processes could contribute to long-term atmospheric variability by passing their relatively slow anomalous signals to the atmosphere. A large number of studies have provided evidence for this contribution (e.g., Yeh et al. 1984; Dickinson and Handerson-Sellers 1988; Xue and Shukla 1993; Delworth and Manabe 1989; Vinnikov et al. 1996; Liu and Avissar 1999; Koster and Suarez 2001; Robock et al. 2003).

Understanding the importance of soil moisture memory to monthly and seasonal atmospheric variability has been a goal of the Global Energy and Water Cycle Experiment (GEWEX). Measurements of land-atmosphere variability were made and models were developed to study the relationships between soil and atmospheric processes in the GEWEX Continental-Scale International Project (GCIP) and GEWEX Asian Monsoon Experiment (GAME), which were conducted in the Mississippi River area of the USA and the Huaihe River area of China, respectively. The GEWEX America Prediction Project (GAPP) has established a goal to develop and demonstrate a capacity to make reliable monthly and seasonal predictions of precipitation and land-surface hydrologic processes using soil moisture memory.

The purpose of this paper is to review studies on monthly and seasonal variability of the land-atmosphere system, including those that the author participated in. The importance of various land properties is first discussed in Section 2. Four specific issues of time scales, persistence, spatial relations, and prediction are then discussed in Sections 3-6, with the focus on soil moisture. A perspective on future research is given in Section 7. (For a review of landsurface processes and their representation in weather and climate models, readers are referred to the paper by Yang 2003.)

\section{The Importance of Land Properties}

\subsection{Soil Moisture}

Soil moisture of the root zone layer (about 1-2 m deep) and the surface layer (about $0.1 \mathrm{~m}$ deep) can affect long-term and short-term atmospheric processes, respectively. Observational evidence for the importance of the root-zone layer soil moisture has been obtained. Vinnikov et al. (1996) found significant lag autocorrelation over a few months using the soil moisture measurements from Russia. Similar results were obtained for summer months from the soil 
moisture measurements in Illinois of the U.S. (Findell and Eltahir 1997). Eltahir (1998) provided an observational basis for a soil moisture-rainfall feedback mechanism, which linked changes in soil moisture, PBL moist static energy, and rainfall. Koster et al. (2003) provided evidence for the feedback by which precipitation-induced soil moisture anomalies affect subsequent precipitation. Also, evidence of the dominant role of soil moisture in persistence of the land-atmosphere system was presented by analyzing soil moisture measured in China (Liu and Avissar 1999a). However, only a very limited number of observational studies on the monthly and seasonal variability of the land-atmosphere system have been conducted due to the lack in systematic measurements of long-term soil moisture and the difficulty in isolating the signals of land's impacts.

Climate models have been a major tool for studies of monthly and seasonal variability of the land-atmosphere system. Early simulations with atmospheric general circulation models (GCM) coupled with simple land-surface schemes have showed significant impacts of soil moisture on the surface air temperature and precipitation (Mintz 1984). Some of them further indicated that the impacts of initial soil moisture anomalies could last for several months (e.g., Walker and Rowntree 1977; Rind 1982; Rowntree and Bolton 1983; Yeh et al. 1984).

Soil moisture conditions may also contribute to floods and droughts. Both GCM and regional climate models (RegCM) have been used to investigate the role of soil moisture and associated mechanisms. Giorgi et al. (1996) proposed a soil moisture-rainfall feedback which might contributes to the 1988 drought and the 1993 flood in the Midwest U.S. Hong and Pan (2000) found a positive feedback which affects low level structure, and Pal and Eltahir (2001) proposed a positive feedback mechanism linking soil moisture, moist static energy in the $\mathrm{PBL}$, and the frequency and magnitude of convective rainfall processes. Bosilovich and Sun (1999) and Schar et al. (1999) suggested a mechanism linking soil moisture anomaly, change in the low-level jet, and atmospheric moisture change within the flood regions.

\subsection{Soil Temperature}

Soil thermal condition is a less important factor for monthly and seasonal variability in comparison with soil moisture and vegetation because of the relatively small heat capacity of soil. Anomalies in soil temperature last less than one month in a system without hydrological interactions (Liu and Avissar 1999b). However, it is possible that the soil thermal condition affects seasonal atmospheric variability through a mechanism other than modifying landsurface energy and water balances. Tang and Zhong (1984) proposed a mechanism of selfsustained oscillation in the land-atmosphere coupled thermal system, in which the oscillation period was found to be about half a year in a soil layer of more than 10 meters deep.

\subsection{Vegetation}

Vegetation can influence long-term atmospheric variability by modifying land-atmosphere energy and water balances. In comparison with bare soil, vegetated soil has a lower albedo and therefore receives more solar radiation for sensible and latent heat transfer. Vegetation affects the water balance by intercepting precipitation, extracting soil water from deep layers 
through transpiration, and resisting runoff. With larger roughness, momentum and turbutent transfers on the surface are changed.

Charney (1975) proposed a bio-geophysical feedback mechanism to explain the prolonged drought in northern Africa. A reduction in vegetation cover in the Sahel due to agricultural activities would lead to increased albedo, which would lead to a reduction in heat transfer from the surface and cooling in the atmosphere. The air would be forced to subside and therefore rainfall is reduced. Simulations with GCMs have indicated that degradation of vegetation conditions such as deforestation and desertification would lead to an increase in the surface temperature and a decrease in soil moisture, evaporation, runoff, and possibly precipitation in most cases (Dickinson and Henderson-Sellers 1988; Xue 1997). Vegetation interaction may also contribute to climate variability at interannual and decadal scales (Zeng et al. 1999; Guillevic et al. 2000).

A limitation in simulating the roles of vegetation in seasonal variability is that vegetation is prescribed or constant in most land-surface models. Solutions to this problem have been explored by imposing prescribed seasonal patterns of the evolution of vegetation based on the previously observed cycle of vegetation climatology, or incorporating dynamic vegetation into a land-surface model (GAPP 2000). Ji (1995) developed a climate-vegetation interaction model to simulate the seasonal variations of biomass, energy, and water fluxes for temperate forest ecosystems in northeastern China. Dickinson et al. (1998) added an interactive canopy model to the Biosphere-Atmosphere Transfer Scheme (BATS, Dickinson et al. 1993) to describe the seasonal evolution in leaf area needed in atmospheric models and to estimate carbon fluxes and net primary productivity. Lu et al. (1999) developed and implemented a coupled RAMS/CENTURY modeling system.

\subsection{Snow Cover}

When winter snow melts in the following spring or summer, land-surface heat and water balances can be changed due to heat consumption and liquid water release. This way snow is connected to seasonal atmospheric variability. In addition, snow can directly affect surface radiative balance by increasing the surface albedo.

Robock et al. (2003) investigated the relationship between interannual variations of the monsoon strength and snow cover over Eurasia. They found that the Indian summer monsoon precipitation is negatively correlated with snow cover intensity over Europe in the previous winter and over western Asia in the previous spring, and positively correlated with snow cover over Tibet. The relationship with snow cover over Europe and western Asia is consistent with Bamzai and Shukla (1999).

\subsection{Joint Roles}

Soil moisture, vegetation, and snow cover are closely related. Two or all of them could be involved in a land surface process at the same time. Vegetation often acts in a way similar to soil moisture. For example, soil moisture is reduced due to rainfall interception by vegetation, which leads to less significant persistence (Scott et al. 1995, 1997). Also, both wet and vegetated surfaces have a large water exchange rate, which leads to a short length of the 
seasonal scale in the land-atmosphere system (Liu and Avissar 1999b). The possible role of soil moisture in the effect of snow cover on the subsequent Indian summer monsoon precipitation was investigated by Robock et al. (2003). For the case examined in that study, no evidence for a significant role was found.

Time and space scales of anomalous processes are among the important properties determining relative contributions of soil moisture and other land surface factors. Soil moisture may play more important roles in monthly and seasonal variability than interannual one. It is more important to seasonal precipitation variability at regional scales than continental ones (Liu 2002). Vegetation, on the other hand, may be important in both seasonal and interannual variability. The GAPP science and implementation plan (GAPP 2000) describes in great detail the individual and joint roles of various land properties, development of modeling tools, and major issues to be investigated.

\subsection{Relative Contributions of Land and Ocean Processes}

There are some substantial differences between land and ocean processes. Physically, soil moisture (a hydrological factor) is of major importance for land process, while SST (a thermal factor) is of major importance for ocean processes, which, of course, is due to the fact that the amount of water available for evaporation is unlimited in the ocean, and its thermal capacity is very large. Their relative contributions to seasonal-interannual atmospheric variability depend on geographic and climate regimes (Koster and Suarez 1995; Koster et al. 2000). GCM simulations showed that land surface processes contribute mostly to the variance of precipitation out of the Tropics and in the regions where the strength of land-atmosphere feedback is controlled largely by the relative availability of energy and water there.

Findell and Eltahir $(2003 \mathrm{a}, \mathrm{b})$ used the convective triggering potential and a low-level humidity index to distinguish between three types of early-morning atmospheric conditions (those favoring moist convection over dry soils, those favoring moist convection over wet soils, and those that will allow or prevent deep convective activity, independent of the surface flux partitioning). Analyses of the two measures from radiosonde stations across the contiguous 48 United States reveal that during the summer months positive feedbacks between soil moisture and moist convection are likely in much of the eastern half of the country. Over the western half of the country, atmospheric conditions and the likelihood of moist convection are largely determined by oceanic influences, and land surface conditions in the summer are unlikely to impact convective triggering.

\section{Time Scales of Land-Atmosphere System Variability}

A time scale concerned here represents a period over which an anomalous event spans. It is measured by the length of the period during which the anomalies remain a same sign for nonoscillatory variability, or by the half-length of its time period for oscillatory variability. Atmospheric variability occurs at many time scales, in addition to the sun-forced diurnal and seasonal cycles. Some scales identified include monthly-to-seasonal fluctuations, quasi- 
biannual fluctuations, and the Southern Oscillation ( $\mathrm{SO}$ ) (2-5 years). Abnormal weather events like floods and droughts mostly happen at monthly and seasonal scales.

The atmospheric fluctuations and weather anomalies at these time scales result from interactions between the atmosphere and other components of the climate system. It has been revealed, for example, that ocean-atmospheric interaction is the cause for the SO (Cane 1992). Studies on the time-scales in the land-atmosphere system are aimed at identifying the major scales at which land surface processes can contribute to long-term atmospheric variability and anomalous weather events.

\subsection{Theoretical Framework of Time Scales}

The definition and physical interpretation of time scales can be illustrated using the soil water balance equation, a first-order model (Delworth and Manabe 1988),

$$
d w(t) / d t=P-E-R
$$

where $w$ is soil moisture; $P, E$, and $R$ are precipitation, evapotranspiration, and runoff. Snowmelt is neglected in the model. $P$ is an external forcing. Although varied levels of parameterization schemes are available for $E$ and $R$ (see Yang 2003 for detail), some simple schemes are usually used for scale analyses. $R$ can be related to $P$, and $E$ can be calculated by

$$
E=\left[w(t) / w_{f c}\right] E_{p}
$$

where $E_{p}$ and $w_{f c}$ are potential evaporation, which is determined by meteorological conditions, and soil water field capacity. Precipitation usually has a much faster pace than soil moisture, suggesting that variations of precipitation and soil moisture could be expressed as red noise, $y(t)$, and white noise, $z(t)$, respectively

$$
d y(t) / d t=-\lambda y(t)+z(t)
$$

This represents a system possessing an inherent exponential damping with a rate of $\lambda=E_{p} / w_{f c}$. The reciprocal of the rate is the $e$-folding time $=1 / \lambda=w_{f c} / E_{p}$, that is, the time of a period during which a disturbance is reduced to $e^{-1}$ times of its initial amplitude. This time is used to measure time scale of soil moisture variability. $\lambda$ can be related to time-lag autocorrelation function

$$
r(\tau)=-e^{\lambda \tau},
$$

where $r$ and $\tau$ are autocorrelation and time lag, respectively. It can be seen from Eqs. 2 and 3 that major contributing factors for restoring soil moisture to its normal status are potential evaporation and soil water field capacity. Eq. 4 indicates that the longer the time scale is, the more closely consequent soil moisture is related its to initial anomaly. 
A fourth-order model can be developed based on the energy and water conservation equations of the soil and atmosphere, which determines damping rates of soil moisture, soil temperature, air humidity, and air temperature with the effects of various interactions (e.g., Liu and Avissar 1999b). By assuming no disturbance with soil moisture in the fourth-order model, a third-order model can be obtained. There are no interactions between soil moisture and other model variables. Similarly, three other third-order models can be obtained by assuming no disturbance with soil temperature, air humidity, or air temperature in the fourthorder model. Four second-order models can be obtained by assuming no disturbance with any two of the four system variables. Finally, by assuming no interactions among the four system variables, the fourth-order model becomes four independent first-order models, each of which contains only one of the four variables. In these cases, the variation of the disturbance in the models is caused by self-feedback.

\subsection{Scales in Land-Atmosphere System}

Using the first-order model described by Eqs. (1-4), Delworth and Manabe (1988) obtained a globally averaged scale of soil moisture variability of about one to two months based on the simulations with the Geophysical Fluid Dynamics Laboratory (GFDL) GCM. Using the same technique, a value of three months was obtained based on the soil moisture measurements in Russia (Vinnikov et al. 1996) and about two and half months based on the soil moisture measurements in North China (Entin et al. 2000).

Interactions between soil moisture and other variables included in some higher-order models (Liu et al. 1993; Liu and Avissar 1999b; Liu and Avissar 2003) can significantly increase the length of a scale. In a fourth-order model (Liu and Avissar 1999b), the atmosphere is assumed to consist of an air column and the soil is assumed to consist of a thermally active layer and of a hydrologically active layer. Radiation, cloud and precipitation, sensible and latent heat (evaporation) fluxes are calculated based on various parameterization schemes. The time scales represented by the four solutions of the fourth-order model are of the orders of one day, one week, two months, and eight months (Table 1). The two longer scales represent monthly- and seasonal-scale processes, respectively. The seasonal scale appears only in those third- or second-order models that include disturbance of soil moisture. The longest scale varies between about 190 and 240 days. This emphasizes that the soil moisture feedback, and its interactions with the other variables, are the primary cause for the scale. In the model without soil moisture disturbance, the maximum time scale is only about two months. In addition, among the various interactions, the one between soil moisture and air humidity is the predominant: excluding this interaction results in a reduction in the length of the seasonal scale by more than one month. Without any interactions (results of first-order models), the longest scale caused by soil moisture self-feedback is only about three and a half months.

These studies suggested that the major scales at which land surface processes could affect the long-term atmospheric variability are monthly and seasonal ones. Because of the lack of long-term soil moisture measurements, it is difficult to find observational evidence for the scale features obtained from the simple models of water and energy conservation equations. 
However, global climate models have provided some numerical evidence (e.g., Yeh et al. 1984; Liu et al. 1992 a, b; and Liu and Avissar 1999a). Yeh et al (1984) conducted a numerical experiment of initial soil moisture forcing with a simplified GFDL GCM, and showed that the induced anomalies in evaporation, precipitation, and soil moisture last for three to five months. The time scales calculated using a 10-year simulation with the NCAR Community Climate Model version 2 (CCM2) coupled with BATS (Dickinson et al. 1993) range between about two months in the tropics and over eight months at high latitudes (Liu and Avissar 1999a).

Table 1 Damping times of the fourth- and third-order models (in days) (From Liu and Avissar 1999b)

\begin{tabular}{|l|l|rrrr|}
\hline Model & Variables & \multicolumn{4}{|c|}{ Scales } \\
Order & Inactivated & 1 & 2 & 3 & 4 \\
\hline 4th & None & 232 & 58 & 6 & 1 \\
\hline 3 rd & Air Temperature & 229 & 7 & 1 & \\
& Air Humidity & 196 & 19 & 1 & \\
& Soil Temperature & 236 & 29 & 6 & \\
& Soil Moisture & 58 & 6 & 1 & \\
\hline
\end{tabular}

\subsection{Impacts of Physical Parameters}

A technique called Fourier Amplitude Sensitivity Test (FAST) was used to identify which parameters mostly affect the scales obtained from the fourth-order land-atmosphere model (Liu and Avissar 1999b). This technique was introduced by Cukier et al. (1973) and was used, for example, by Liu and Avissar (1996) to examine sensitivity of shallow convective precipitation to atmospheric dynamic and cloud microphysical parameters.

A number of parameters were found to have a very strong impact on the seasonal scale. Basically, the smaller the fluxes of water in the land-atmosphere system (i.e., evaporation, runoff, and underground diffusion), the longer the scale is. As a result, a moister soil, a higher soil temperature, more solar radiation, larger potential evaporation, or stronger turbulent activity (thus a larger actual evaporation rate) leads to a smaller length of the scale.

\section{Persistence}

It has long been recognized that atmospheric anomalies can persist over relatively long time periods (i.e., months to seasons), a feature known as persistence of atmospheric disturbances. The significance of this feature is that, if a variable has strong persistence, the variable itself can be a good predictor for predicting its variability. Using autocorrelations between adjacent monthly or seasonal atmospheric variables, Namias (1952) demonstrated the existence of such persistence.

Land can contribute to the atmospheric persistence through its long memory and interaction with the atmosphere. For example, following a dry spring, soil would likely be desiccated during the summer. This would result in a relatively large sensible heat flux injected in the atmosphere at the ground surface, which could perhaps maintain anticyclonic circulations. Under such circumstances, one could expect reduced summer rainfall. A 
theoretical framework of the role of soil moisture memory in precipitation statistics was presented by Koster et al. (2000), which indicates that a larger soil moisture memory would lead to a larger correlation between initial precipitation and its subsequent variability. Studies of the persistence issue are aimed at understanding the features of persistence in the landatmosphere system and the contribution of land surface processes.

\subsection{Features of Soil Moisture Persistence}

Persistence of the land-atmosphere system has been investigated by analyzing the natural variability of long-term simulations produced with GCMs (e.g., Delworth and Manabe 1988, 1989; Manabe and Delworth 1990). Using multi-year simulations produced with the GFDL GCM, Delworth and Manabe $(1988,1989)$ analyzed the variability in soil moisture and atmospheric variables, and tried to identify relationships between them. They found that persistence of soil moisture is statistically significant, and is more intensive at high latitudes and during winter seasons.

Persistence also depends on climate regime: it is more significant in drier geographic regions. Figure 1 presents one-month lag autocorrelation coefficients of four variables obtained from measurements in China (Liu and Avissar 1999a). Because of the unavailability of soil moisture data in North China during winter time due to frozen soil, one-month lag autocorrelations were calculated only for the months of April to October. For soil moisture, the one-month lag autocorrelation coefficients are less than $55 \%$ in the moist Southeast China, and over $80 \%$ in the dry Northwest China, indicating increased significance of persistence from the moist region to the dry one. Persistence of other three variables (soil temperature, air humidity and temperature) has the same dependence on climate regime as soil moisture. In addition, a global analysis (Liu and Avissar 1999a) based on the CCM2 simulation (Bonan 1994) obtained relatively large autocorrelation coefficients in dry northern Africa, and the strong contrast between this region and the moist tropics, where autocorrelation coefficients are relatively low.

\subsection{Physical Mechanisms}

Actual evaporation was found to be a major factor determining the seasonal persistence in the land-atmosphere system (Liu and Avissar 1999b). Persistence of soil moisture is inversely proportional to evaporation. At high latitudes and in dry regions, actual evaporation is low, resulting in strong persistence. Furthermore, because water exchanges between the land surface and its overlying atmosphere are dominant in dry regions, as indicated by a large ratio of evaporation to precipitation (or small runoff) obtained in these regions, soil moisture has a significant impact on atmospheric persistence. By contrast, soil moisture has a smaller impact in the tropics and at high latitudes, where water exchanges between the atmosphere in these regions and its surroundings are more important.

It was indicated that soil moisture plays a critically important role in the persistence of the land-atmosphere system (Liu and Avissar 1999a). Soil moisture has the strongest persistence among various land and atmospheric variables. The one-month autocorrelation coefficients are over $30 \%$ anywhere on the globe, with a global average of about $60 \%$. 
Persistence of soil temperature was also found in most parts of the globe. However, its intensity is much weaker than that of soil moisture. Persistence of atmospheric variables is found only in some regions.
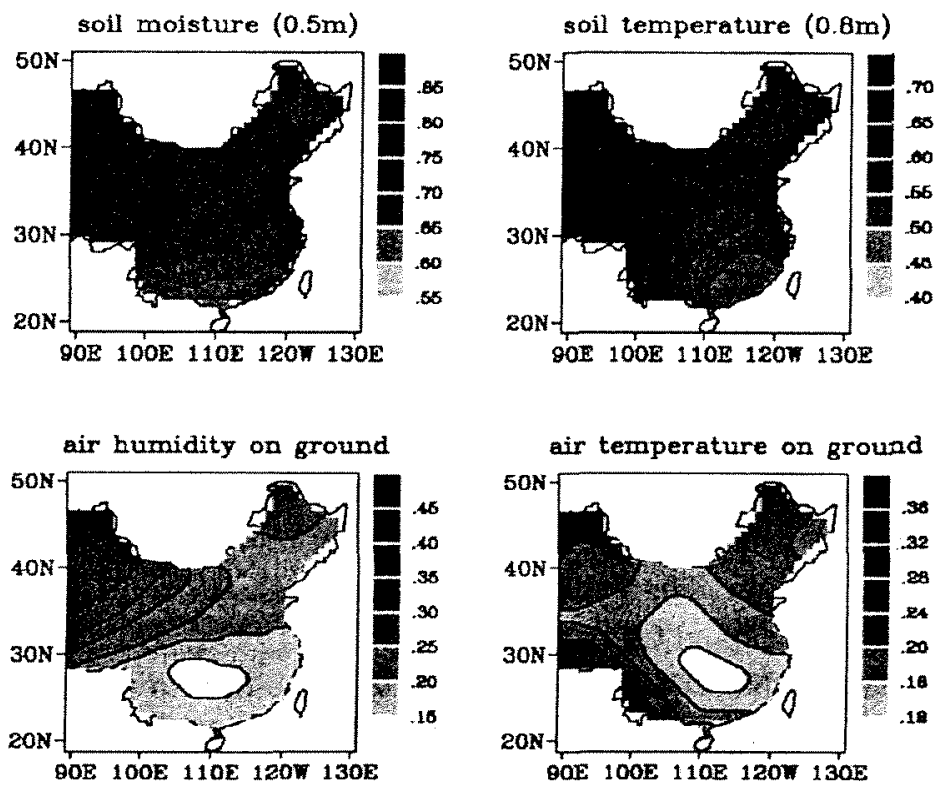

Figure 1. One-month lag correlation coefficients (After Liu and Avissar 1999a).

\section{Spatial Relations}

\subsection{Singular Value Decomposition (SVD) Patterns}

Unlike soil moisture, whose status is determined by local hydrological processes (rainfall reaching the surface, evapotranspiration, and runoff), precipitation is controlled by both large-scale circulation patterns and local land-atmosphere exchanges. How strong land surface can affect precipitation depends on the relative importance of the two processes. It is assumed that the local processes may play more important roles for certain spatial patterns of soil moisture and precipitation.

Relations in spatial patterns between soil moisture and precipitation have been investigated by applying techniques such as principal component analysis (PCA). Wang and Kumer (1998), for example, used empirical orthogonal function (EOF) to analyze soil moisture patterns and the effects on variability of the surface climate in the USA. Another PCA technique called singular value decomposition (SVD) (Bretherton et al. 1992) was used to identify soil moisture patterns closely connected to precipitation variability in China (Liu 2002). This technique realizes separation of each of the two fields into space patterns and time coefficients (expansion coefficients). Sorted in declined order of singular values, response between the first pair of spatial patterns is the largest, that between the second pair 
is the second largest, and so on. The first several pairs of modes are regarded as SVD leading modes.

The soil moisture and precipitation data used in the SVD analysis were simulated with the NCAR regional climate model (RegCM) (Dickinson et al. 1989; Giorgi and Bates 1989; Giorgi et al. 1999). This model is a tool for studying regional features of climate and landsurface processes at geographic regions of interest. It was developed based on NCAR / Pennsylvania State University Mesoscale Model Version 4 (MM4) (Anthes et al. 1987). Some detailed parameterization schemes were incorporated, including BATS land-surface physics (Dickinson et al. 1993) and the NCAR radiative transfer model. RegCM was able to reproduce some important high-resolution spatial characteristics of climate over East Asia (e.g., Liu et al. 1994, 1996; Liu and Ding 1995).

Four leading modes of soil moisture (Figure 2) were identified by the SVD analysis. The spatial pattern of the 1st soil moisture mode consists of a pair of positive and negative anomalies separated between $32-35^{\circ} \mathrm{N}$. The anomalous regions are basically zonally oriented, each of which is about 30 degrees long and 15 degrees wide. The 2 nd mode represents a pattern of more or less meridionally oriented anomalies. There is a large area of negative anomaly spreading from Mongolia and Northeast China down southwestward to Central China. The 3 rd mode is similar to the 2 nd mode in terms of its meridional orientation, but the negative region in the north does not spread over Mongolia, and its intensity is much weaker. The last mode is featured by varied anomalies which are negative in Northeast China and become positive southwestward down to Central China.

Based on the corresponding atmospheric patterns, the SVD leading modes of soil moisture were divided into two types. Type I consists of the 1st and 4th soil moisture SVD modes, whose corresponding atmospheric anomalous patterns are featured by strong relations in the middle latitudes of $500 \mathrm{hPa}$ and by the same signs of anomalies between the middle and low troposphere; Type II consists of the 2nd and 3rd modes, whose corresponding atmospheric patterns are featured by comparable importance between the atmospheric systems in the middle and low latitudes and by opposite signs between the middle and low troposphere in some regions.

\subsection{Temporal Relations}

The two types of soil moisture SVD modes have different importance to subsequent precipitation. The time-lag correlation of the SVD expansion coefficient series between soil moisture and precipitation (Figure 3) is more significant for the Type II than Type I SVD patterns of soil moisture. For both patterns of the 2 nd and 3 rd modes, the correlation coefficients with soil moisture leading precipitation are significant for the lag-time up to six months at the $99.9 \%$ confidence level (the critical correlation value of $30 \%$ ). In contrast, those for the patterns of the 1 st and 4th modes are only barely significant for the lag-time of one month at the confidence level.

The above results indicate that, among the SVD leading patterns of soil moisture, only those of Type II have close relations to subsequent variability of precipitation. Some explanations were obtained based on the features of their corresponding atmospheric patterns, 
that is, opposite signs of anomalies between the middle and low troposphere, and significant anomalies at both middle and low latitudes. The first feature usually indicates a weak control of an atmospheric system. As a result, soil moisture plays a relatively important role in variability of precipitation. In contrast, the same signs of atmospheric anomalies between the two heights for the Type I SVD patterns usually indicate a strong control of an atmospheric system throughout the entire troposphere. In this case, soil moisture's role is less significant. The second feature may reflect a low westerly index, i.e., anomalously strong planetary-wave activities. This favors the development of synoptic systems which have small scales and move fast. Their effects on long-term atmospheric processes are very limited. As a result, the role of soil moisture becomes relatively important.
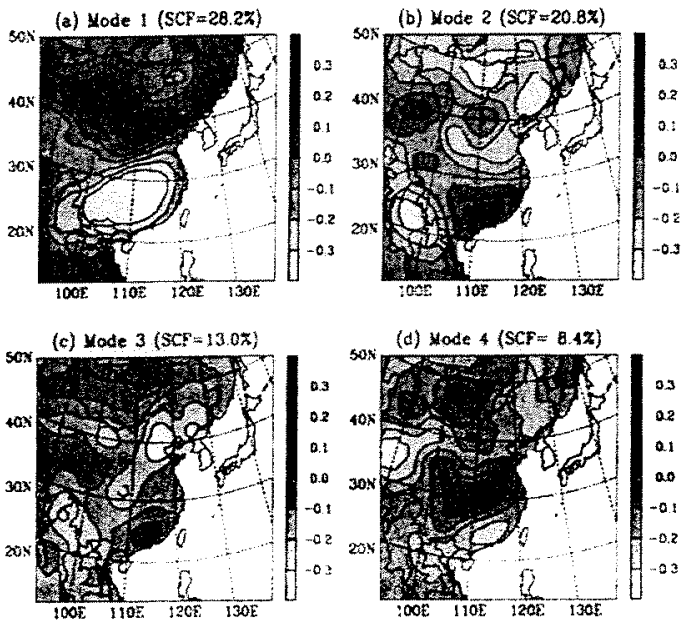

(d) Hode 4 (Scr $=4.4 x)$

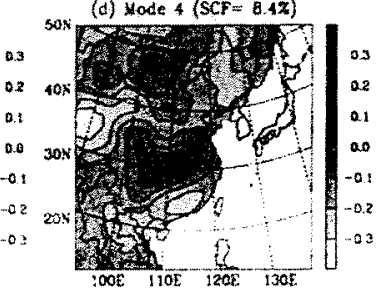

Figure 2. Soil moisture SVD patterns coupled with precipitation (After Liu 2002).

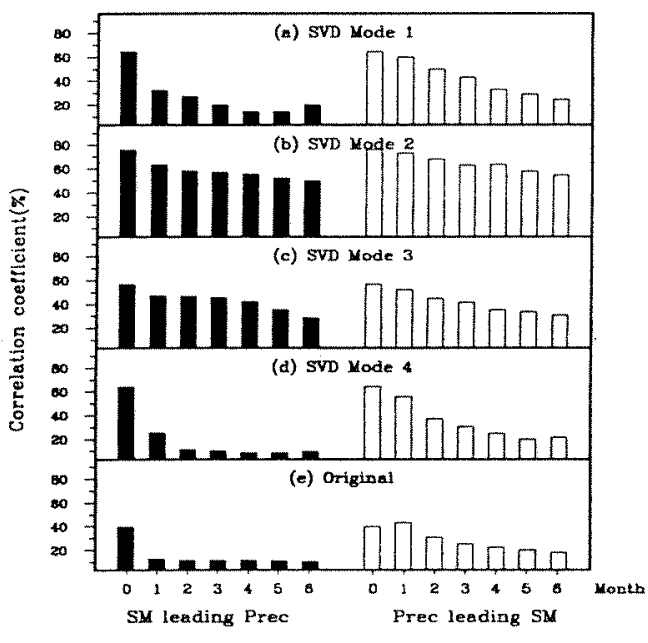

Figure 3. Time-lag correlation coefficients between soil moisture (SM) and precipitation (Prec) (After Liu 2002).

\subsection{Predictive Significance}

The significance of the SVD patterns to monthly and seasonal prediction was illustrated by comparing the time-lag correlation with soil moisture leading precipitation between the SVD modes (Fig. 3a-d) and the original data series (Fig. 3e). The coefficients in Fig. 3e were obtained by first calculating time-lag correlation coefficients at each location and then obtaining space average of their absolute values. Although the simultaneous correlation coefficient (zero-lag month) of $40 \%$ is comparable to those of the SVD leading modes, the correlation coefficients of the original data series with soil moisture leading precipitation by one month or longer are only about $15 \%$.

This result suggests that, if using soil moisture as a predictor to forecast monthly and seasonal precipitation variability, better predictability could be achieved by using the SVD patterns than original data at individual locations of the predictor. There are also differences in the time-lag correlation between precipitation and subsequent soil moisture variability 
between the original data series and the SVD expansion series, though not as large as those in the time-lag correlation between soil moisture and subsequent precipitation variability.

\section{Prediction}

The importance of land-surface conditions to short- and medium-term weather forecasts has been recognized. A number of operational and research models, including the NCEP ETA model (Black 1994), NCAR/Penn State MM5 (Grell et al. 1994), Regional Atmospheric Modeling System (RAMS) (Pielke et al. 1992), have been coupled with land-surface parameterization schemes to include the impacts of land-surface conditions on sensible and latent heat fluxes, PBL, atmospheric stability, and clouds and precipitation. There is also evidence, including that described above, for the importance of soil moisture to long-term weather forecast. As described below, dynamic and statistical methods have been used to estimate predictability and to develop forecast techniques.

\subsection{Dynamical Method}

This method basically tests significance of simulated responses in the surface air temperature, precipitation, and soil moisture to initial soil moisture forcing with land-atmosphere coupled climate models. The response could be measured by the differences in the variables between simulations with and without the initial soil moisture forcing. The role of ocean processes is excluded by using prescribed SST. The ensemble technique is often used to compare two or more groups of multiple simulations. Studies by Schlosser and Milly (2002) and Dirmeyer (2003) showed generally higher predictability of the surface air temperature, consistent with the resulted obtained from reanalysis data (e.g., Huang et al. 1996). Predictability of precipitation was found to be much lower, but for some specific situations such as transition zones between dry and humid climates, or the regions with a tendency toward large initial soil moisture anomalies and a strong precipitation-evaporation-soil moisture connection, it could be significant (Koster et al 2000; Koster and Suarez 2003).

\subsection{Statistical Method}

This method uses statistical techniques like regression to build relations between initial soil moisture and subsequent variability of precipitation or other variables. Soil moisture could be a sole predictor or combined with others like SST. Traditionally a regression relation has been built for a specific location. Because precipitation at a given location is determined by the combined effects of systematic relationships, which mostly are of large spatial scale, identifying its spatial pattems and utilizing them as prediction factors can enhance predictive skill at individual locations (Barnston 1994). Some tools like PCA have been applied to obtaining spatial patterns of soil moisture and precipitation aimed at improving skills of prediction models (e.g., Mo 2002).

Predictability of monthly and seasonal precipitation could be improved by using SVD patterns between soil moisture and precipitation instead of their values at individual locations. 
A recent study provided predictive evidence for this suggestion by comparing skills of two statistical prediction models based on the coupled SVD patterns and local relationships (Liu 2003). The data used for model development and validation were obtained from the simulation over East Asia with RegCM (Liu 2002). The results showed much improved skill with the prediction model using the coupled SVD patterns. The seasonal prediction skill is higher than the monthly one. The most remarkable contribution of soil moisture to the prediction skill is found in warm seasons, opposite to that of SST.

\section{Discussion}

The major findings from the studies reviewed in this paper are as follows:

a. Land processes have significant contribution to long-term variability of the landatmosphere system at time scales up to seasons. Self-feedback of soil moisture is a major contributor to the seasonal scale and the interactions between soil moisture and other components of the system can remarkably increase the length of the seasonal scale.

b. Land processes are more important than ocean processes to seasonal variability of precipitation over the mid-latitude continents. Vegetation could contribute to interannual and decadal variability of precipitation.

c. Persistence of soil and atmospheric variables, especially soil moisture, is a basic feature of long-term variability of the land-atmosphere system. It is more significant in high latitudes, during winter seasons, and in arid regions. The rate of actual evaporation, which is dependent on soil water content, is a major factor determining the persistence.

d. Among various spatial SVD patterns of soil moisture in East Asia, only those corresponding to the atmospheric anomalous patterns with opposite signs between the middle and low troposphere and significant anomalies at both middle and low latitudes have close relations to subsequent monthly and seasonal precipitation variability.

e. There is high predictability of monthly and seasonal variability in the surface air temperature when soil moisture is used as a predictor. Predictability of monthly and seasonal variability in precipitation is generally low, but it could be significant in certain climatic regions. Application of spatial relations like soil moisture SVD patterns can improve statistical predictability of precipitation.

The lack of soil moisture data has been a major difficulty in studying the issues discussed above. This problem will remain for quite a while. A number of research projects like GCIP have made efforts to obtain more frequent and higher-resolution measurements of soil moisture data. This data is valuable for land-surface model development and water and energy balance analysis, but their relatively short length presents a problem to the studies of long-term variability. The application of remote sensing is believed to be one possible solution for global coverage of high-resolution soil moisture data, which is useful for obtaining initial fields for simulation and prediction. One limitation with the technique is that only soil moisture of a thin layer can be detected, which is much less valuable than soil moisture of a deep layer to studies on long-term variability.

Techniques have been under development to create alternative data of soil moisture measurements by using land-surface hydrological models with observed/assimilated precipitation. The application of such precipitation is expected to produce more reliable soil 
moisture. Among various types of data are the NCEP global reanalysis (Kalnay et al. 1996), which has been used in the issues discussed here (e.g., Huang et al. 1996), the NCEP regional reanalysis (Mesinger et al. 2003), which will be available soon, and the GEWEX/Global Land-Atmosphere System Study (GLASS) outputs (Dirmeyer 2002).

Most studies on the role of land processes in monthly and seasonal variability of the landatmosphere system have been conducted using land-atmosphere coupled models. Our understanding of the variability, therefore, is affected by uncertainties with the models. One example of model uncertainty is coupling strength (Koster et al. 2002). There is a need for continuously improving calculation schemes of various land-surface processes, including snow pack, frozen soil, vegetation, and landscape heterogeneity.

An objective of developing and demonstrating the capacity of making reliable monthly and seasonal predictions of precipitation and land-surface hydrologic processes using soil moisture memory was recently developed with GAPP. This raises some new issues about the monthly and seasonal variability of the land-atmosphere system. It presents some new challenges and, at the same time, new opportunities for scientists for many years to come.

Acknowledgments I would like to thank three anonymous reviewers whose comments significantly improved the manuscript. One of the reviewers kindly checked English grammar and usage. I also thank Dr. Xun Zhu for his encouragement, and Tim Giddens for editorial check. This research was supported by the National Aeronautics and Space Administration under grant NAG8-1513.

\section{References:}

Anthes, R. A., E.-Y. Hsie, and Y.-H. Kuo, 1987: Description of the Penn State/NCAR Mesoscale Model Version 4 (MM4), Technical Note, NCAR/TN-282+STR, National Center for Atmospheric Research, Boulder, Colorado, 66 pp.

Avissar, R., 1995: Recent Advances in the representation of land-atmosphere interactions in global climate models, Rev. Geophys., 33, 1005-1010.

Avissar, R., and Y. Liu, 1996: A three-dimensional numerical study of shallow convective clouds and precipitation induced by land-surface forcings, J. Geophys. Res., 101, 7499-7518.

Bamzai, A. S., and J. Shukla, 1999: Relation between Eurasia snow cover, snow depth, and the Indian summer monsoon: An observational study, J. Clim., 12, 3117-3132.

Betts, A. K., J. H. Ball, and Coauthors, 1996: The land-surface atmosphere interaction: A review based on observational and global modeling perspectives, J. Geophys. Res., 101, 7209-7226.

Black, T., 1994: The new NMC mesoscale Eta model: description and forecast examples, Wea. Forecasting, 9, 265-278.

Bonan, G. B., 1994: Comparison of the land surface climatology of the NCAR CCM2 at R15 and T42 resolutions with implications for sub-grid land surface heterogeneity. J. Geophys. Res., 99, 1035710364.

Bosilovich, M. G., and W.-Y. Sun, 1999: Numerical simulation of the 1993 Midwestern flood: landatmosphere interactions, J. Clim., 12, 1490-1505.

Bretherton, C. S., C. Smith, and J. M. Wallace, 1992: An intercomparison of methods for finding coupled patterns in climate data, J. Clim., 5, 541-560. 
Cane, M. A., 1992: Tropical Pacific ENSO models: ENSO as a mode of the coupled system, in “Climate System Modeling" (Ed. K.E. Trenberth), The Press of the Uni. Of Cambridge, $788 \mathrm{pp}$.

Charney, J. B., 1975: Dynamics of deserts and drought in the Sahel, Q.J.Roy. Meteor. Soc., 101, 193202.

Chen, F. and R. Avissar, 1994: Impact of land--surface moisture variability on local shallow convective cumulus and precipitation in large-scale models, J. Appl. Meteor., 33, 1382-1401.

Cukier, R. I., C. M. Fortuin, and Coauthors, 1973: Study of the sensitivity of coupled reaction systems to uncertainties in rate coefficients. I. Theory. J. Chem. Phys., 59, 3873-3878.

Delworth, T. and S. Manabe, 1988: The influence of potential evaporation on the variabilities of simulated soil wetness and climate, J. Clim., 1, 523-547.

Delworth, T. and S. Manabe, 1989: The influence of soil wetness on near-surface atmospheric variability. J. Clim., 2, 1447-1462.

Delworth, T. and S. Manabe, 1993: Climate variability and land-surface processes, Adv. Water Resour., 16, 3-20.

Dickinson, R. E., and A. Henderson-Sellers, 1988: Modeling tropical deforestation: A study of GCM land-surface parameterizations, Quart. J. Roy. Meteor. Soc., 114, 439-462.

Dickinson, R. E., R. M. Errico, F. Giorgi, and G. T., Bates, 1989: A regional climate model for the western U.S., Clim. Change, 15, 383-422.

Dickinson, R. E., A. Henderson-Sellers, and P. J.Kennedy, 1993: Biosphere-Atmosphere Transfer Scheme (BATS) Version IE as Coupled to the NCAR Community Climate Model, NCAR Tech. Note/TN-387, National Center for Atmospheric Research, Boulder, CO., 72pp.

Dickinson, R. E., M. Shaikh, R. Bryant, and L. Graumlich, 1998: Interactive canopies for a climate model. J. Clim., 11, 2823-2836.

Dirmeyer, P. A., 2002: Second GEWEX/GLASS Global Soil Wetness Project (GSWP2), in "Mississippi River Climate \& Hydrology Conference", May 13-17, New Orleans, LA, P.54.

Dirmeyer, P. A., 2003: The role of the land surface background state in climate predictability, $J$. Hydrometeor., 4, 599-610.

Eltahir, E. A. B., 1998: A soil moisture-rainfall feedback mechanism. 1. Theory and observations, Water Resour. Res., 34, 765-785.

Entekhabi, D., I. Rodriguez-Iturbe, and R. I. Bras, 1992: Variability in large-scale water balance with land surface-atmosphere interaction, J. Clim., 57, 798-813.

Entin, J. K., A. Robock, and Coauthors, 2000: Temporal and spatial scales of observed soil moisture variations in the extratropics. J. Geophys. Res., 105, 11,865-11,877.

Findell, K. L. and E. A. B. Eltahir, 1997: An analysis of the soil moisture-rainfall feedback, based on direct observations from Illinois, Water Resour. Res., 33, 725-735.

Findell, K. L., and E. A. B. Eltahir, 2003a: Atmospheric controls on soil moisture-boundary layer interactions. Part I: Framework development, J. Hydrometeorol., 4, 552-569.

Findell, K. L., and E. A. B. Eltahir, 2003b: Atmospheric controls on soil moisture-boundary layer interactions. Part I: Feedbacks within the continental United States, J. Hydrometeorol., 4, 570583.

GAPP, 2000: GEWEX Americas Prediction Project (GAPP) Science Plan and Implementation Strategy, $160 \mathrm{pp}$.

Giorgi, F., and G. T. Bates, 1989: The climatological skill of a regional model over complex terrain. Mon. Wea. Rev., 117, 2325-2347. 
Giorgi, F., L. O. Means, C. Shields, and L. Mayer, 1996: A regional model study of the importance of local versus remote controls of the 1988 drought and the 1993 flood over the Central United States, J. Clim., 9, 1150-1162.

Giorgi, F., Y. Huang, K. Nishizawa, and C. Fu, 1999: seasonal cycle simulation over eastern Asia and its sensitivity to radiative transfer and surface processes, J. Geophys. Res., 104, 6403-6424.

Grell, A. G., J. Dudhia, and D. R. Stauffer, 1994: A Description of the Fifth-Generation Penn State/NCAR mesoscale Model (MM5), NCAR Tech. Note, 398, 122pp.

Guillevic, P., R. D. Koster, and Coauthors, 2002: Influence of the interannual variability of vegetation on the surface energy balance-A global sensitivity study, J. Hydrometeor., 3, 617-629.

Hong, S.-Y., and H.-L. Pan, 2000: Impact of soil moisture anomalies on seasonal summertime circulation over North America in a regional climate model, $J$. Geophys. Res., 105, 29625-29634.

Huang, J., H. M. van den Dool, and K. P. Georgakakos, 1996: Analysis of model calculated soil moisture over the United States (1931-1993) and applications to long-range temperature forecasts, J. Clim., 9, 1350-1362.

Kalnay, E., M. Kanamitsu, and Coauthors, 1996: The NCEP/NCAR 40-year reanalysis project, Bull. Amer. Met. Soc., 77, 437-471.

Koster, R. D. and M. J. Suarez, 1995: Relative contributions of land and ocean processes to precipitation variability, J. Geophys. Res-Atoms., 100 (D7), 13775-13790.

Koster, R. D. and M. J. Suarez, 1996: The influence of land surface moisture retention on precipitation statistics, J. Clim., 9, 2551-2567.

Koster, R. D., M. J. Suarez, and M. Heiser, 2000: Variance and predictability of precipitation at seasonal-to-interannual timescales, on precipitation, J. Hydrometeor., 1, 26-46.

Koster, R. D. and M. J. Suarez, 2001: Soil moisture memory in climate models, J. Hydrometeor., 2 , 558-570.

Koster, R. D., P. A. Dirmeyer, and Coauthors, 2002: Comparing the degree of land-atmosphere interaction in four atmospheric general circulation models, $J$. Hydrometeor, 3, 363-375.

Koster, R. D. and M. J. Suarez, 2003: Impact of land surface initialization on seasonal precipitation and temperature prediction, J. Hydrometeor., 4, 408-423.

Koster, R. D., M. J. Suarez, and Coauthors, 2003: Observational evidence that soil moisture variations affect precipitation, Geophys Res. Lett., 30(5), art. No. 1241.

Ji, J. J. and Y. C. Hu, 1989: A simple land surface process model for use in climate study, Acta, Meteorologica Sinica, 3, 342-351.

Ji, J. J., 1995: A climate-vegetation interaction model: simulating physical and biological processes at the surface, Journal of Biogeochemistry, 22, 2063-2068.

Liu, Y.-Q., D. Z. Ye, and J. J. Ji, 1992a: Influence of soil moisture and vegetation on climate. I: A theoretical analysis on persistence of short-term climatic anomalies. Science in China, 35, 441448.

Liu, Y.-Q., D. Z. Ye, and J. J. Ji, 1992b: Influence of soil moisture and vegetation on climate changes induced by thermal forcing, Acta Meteor. Sinica, 6, 58-69.

Liu, Y.-Q., D. Z. Ye, and J. J. Ji, 1993: Influence of soil moisture and vegetation on climate. II: numerical experiments on persistence of short-term climatic anomalies. Science in China, 36B, 6.102-109.

Tiu, Y.-Q., F. Giorgi, and W. M. Washington, 1994: Simulation of summer monsoon climate over East Asia with an NCAR regional climate model, Mon. Wea. Rev., 122, 2331-2348. 
Liu, Y.-Q., and Y. H. Ding, 1995: A review of the study on simulation of regional climate, Q.J. App. Meteor., 6, 228-239 (in Chinese).

Liu, Y.-Q. and R. Avissar, 1996: Sensitivity of shallow convective precipitation induced by lan surface heterogeneities to dynamical and cloud microphysical parameters, J. Geophys. Res., 101 $7477-7497$.

Liu, Y.-Q., R. Avissar, and F. Giorgi, 1996: A simulation with the regional climate model (RegCM2. of extremely anomalous precipitation during the 1991 East-Asia flood: An evaluation study. $J$ Geophy. Res., 101, 26199-26215.

Liu, Y.-Q., and R. Avissar, 1999a: A study of persistence in the land-atmosphere system using a general circulation model and conservations, J. Clim., 12, 2139-2153.

Liu, Y.-Q., and R. Avissar, 1999b: A study of persistence in the land-atmosphere system with a fourthorder analytical model, J. Clim., 12, 2154-2168.

Liu, Y.-Q., C. P. Weaver, and R. Avissar, 1999: Toward a parameterization of mesoscale fluxes and moist convection induced by landscape heterogeneity, J. Geophy. Res., 104, 19515-19534.

Liu, Y.-Q., 2002: Spatial patterns of soil moisture connected to monthly-seasonal precipitation variability in a monsoon region, $J$. Geophy. Res. (in press).

Liu, Y.-Q., 2003: Prediction of monthly-seasonal precipitation using coupled SVD patterns between soil moisture and subsequent precipitation, J. Geophys. Lett., 30 (15), 1827, doi:10.1029/2003GL017709.

Liu, Y.-Q., and R. Avissar, 2003: Modeling of the global water cycle - analytical models (1st, 2nd, 3rd, 4th order, in "The Encyclopedia of Hydrological Sciences", John Wiley \& Sons (in preparation).

Lu, L., R.A. Pielke, and Coauthors, 2001: Implementation of a two-way interactive atmospheric and ecological model and its application to the central United States. J. Clim., 13, 900-919.

Manabe, S., and T. Delworth, 1990: The temporal variability of soil wetness and its impact on climate. Clim. Change, 16, 185-192.

Mesinger, F., G. DiMego, and Coauthors, 2003: NCEP regional reanalysis, Symp. on Observing and Understanding the Variability of Water in Weather and Climate, AMS Annual Meeting, Long Beach, CA, Feb. 2003.

Mintz, Y., 1984: The sensitivity of numerically simulated climate to land-surface boundary conditions, The Global Climate, Houghton, J. T., Ed., Cambridge University Press, 79-105.

Namias, J., 1952: The annual course of month-to-month persistence in climatic anomalies. Bull. Amer. Meteor. Soc., 33, 279-285.

Pal, J. S., and E. A. B. Eltahir, 2001: Pathway relating soil moisture conditions to future summer rainfall within a model of the land-atmosphere system, J. Clim., 14, 1227-1242.

Pielke, R. A., W. R. Cotton, and Coauthors, 1992: A comprehensive meteorological modeling system RAMS, Meteorol. Atmos. Phys., 49, 69-91.

Rind, D., 1982: The influence of ground moisture conditions in North America on summer climate as modeled in the GISS GCM, Mon. Wea. Rev., 110, 1487-1494.

Robock, A., K. Y. Vinnikov, and Coauthors, 2000: The global soil moisture data bank, Bull. Amer. Meteor. Soc., 81, 1281-1299.

Robock, A., M. Q. Mu, K. Y. Vinnikov, and D. Robinson, 2003: Land surface conditions over Euraia and Indian summer monsoon rainfall, $J$. Geophys. Res., 108(D4), art no. 4131.

Rodriguez-Iturbe, I., D. Entekhabi, and R.I. Bras, 1991: Nonlinear dynamics of soil moisture at climate scales: I. Stochastic analysis, Water Resour. Res., 27,1899-1906. 
Rowntree, P.R. and J.A. Bolton, 1983: Simulation of the atmospheric response to soil moisture anomalies over Europe, Quart. J.R.Met.Soc., 109, 501-526.

Schar, C., D. Luthi, U. Beyerle, and E. Heise, 1999: The soil-precipitation feedback: a process study with a regional climate model, J. Clim., 12, 722-741.

Schlosser, C. A., and P. C. D. Milly, 2002: A model-based investigation of soil moisture predictability and associated climate predictability, J. Hydrometeor., 3, 483-501.

Scott, R., R. D. Koster, D. Entekhabi, and M. J. Suarez, 1995: Effect of a canopy interception reservoir on hydrological persistence in a general circulation model, J. Clim., 8, 1917-1928.

Scott, R., D. Entekhabi, R. D. Koster, and M. J. Suarez, 1997: Timescales of land surface evapotranspiration response, J. Clim., 10, 559-566.

Sellers, P. J., Y. Mintz, Y. C. Sud, and A. Dalcher, 1986: A simple biosphere model (SiB) for use within general circulation models, J. Atmos. Sci., 43, 505-531.

Shukla, J. and Y. Mintz, 1982: Influence of land-surface evapotranspiration on the earth's climate. Science, 215, 1498-1501.

Tang, M. C. and Q. Zhong, 1984: Self-sustained vertical oscillation in a simple climate system, Arch. Met. Geoph. Biocl., Ser.B, 34, 21-37.

Vinnikov, K., A. Robock, N. A. Speranskaya, and C. A. Schlosser, 1996: Scales of temporal and spatial variability of midlatitude soil moisture, J. Geophys. Res., 101, 7163-7174.

Walker, J. M. and P. R. Rowntree, 1977: The effect of soil moisture on circulation and rainfall in a tropical model, Quart. J. Roy. Meteor. Soc., 103, 29-46.

Wang, W. Q. and A. Kumar, 1998: A GCM assessment of atmospheric seasonal predictability associated with soil moisture anomalies over North America, J. Geophy. Res., 103, 28637-28646.

Xue, Y.-K., P. J. Sellers, J. L. Kinter and J. Shukla, 1991: A simplified biosphere model for global climate studies. J. Clim., 4, 345-364.

Xue, Y. and J. Shukla, 1993: The influence of land surface properties on Sahel climate. Part 1: Desertification. J. Clim., 6, 2232-2245.

Xue, Y., 1997: Biosphere feedback on regional climate in tropical North Africa, $Q . J$. Roy. Met. Soc., $123 \mathrm{~B}, 1483-1515$.

Yang, Z.-L., R. E. Dickinson, A. Robock, and K. Y. Vinnikov, 1997: On validation of the snow submodel of the biosphere-Atmosphere Transfer Scheme with Russian snow cover and meteorological observational data, J. Clim., 10,353-373.

Yang, Z.-L., 2003: Modeling land surface processes in short-term weather and climate studies. This volume.

Yeh, T. C., R. T. Wetherald, and S. Manabe, 1984: The effect of soil moisture on the short-term climate and hydrology change-A numerical experiment Mon. Wea. Rev., 112, 474-490.

Zeng, N., J. D. Neelin, K. M. Lau, C. J. Tucker, 1999: Enhancement of interdecadal climate variability in the Sahel by vegetation interaction, Sciences, 286 (5444), 1537-1540.

Zeng, X and R. A. Pielke, 1995: Landscape-induced atmospheric flow and its parameterization in large-scale numerical models, J.Clim., 8, 1156-1177. 